\title{
The structural properties of the protective layer of microlamps under polarization
}

\author{
Vinicius R. S. Cassimiro ${ }^{*}$, Rubens M. Cunha Júnior**, Gustavo P. Rehder**, Inés Pereyra**, \\ Marcelo N. P. Carreño**, Marco I. Alayo**, Márcia C. A. Fantini ${ }^{*}$, Nicolas Trcera*** \\ *Instituto de Física, Universidade de São Paulo (USP) \\ ${ }^{* * E s c o l a ~ P o l i t e ́ c n i c a, ~ U n i v e r s i d a d e ~ d e ~ S a ̃ o ~ P a u l o ~(U S P) ~}$ \\ ***Société Civile Synchrotron SOLEIL, Lucia Beamline \\ *cassimiro.vinicius@gmail.com
}

Keywords: Microlamp, Thin-films, XAS

Abstract

This work reports the production of microlamps and their structural properties after modifications induced by the heating process. Their production consists on films deposited by Plasma Enhanced Chemical Vapor Deposition (PECVD) and sputtering over silicon substrates. The filament, composed by a thin chromium wire, is protected against oxidation by a top thin layer. Four different materials were used as protective layer: $\mathrm{SiC}, \mathrm{SiO}_{\mathrm{x}} \mathrm{N}_{\mathrm{y}}, \mathrm{AIN}$ and $\mathrm{TiO}_{2}$. The protective film is heated by the metallic filament and their chemical and structural properties may change, depending on the time interval and intensity of the applied current (up to $2 \mathrm{~h}$ and 50mA). X-ray absorption near edge spectroscopy (XANES) measurements allowed investigating changes on the properties of the microlamps protective films heated under different polarization conditions. The LUCIA beam line of the synchrotron SOLEIL has a microfocus spot $(3 \times 3 \mu \mathrm{m})$, permitting to evaluate the small thermally affected zone. The results showed that the $\mathrm{SiO}_{x} \mathrm{~N}_{y}$ film is thermally stable with negligible changes on the XANES spectra. A slight AIN oxidation is observed as heating rises, which is particularly evident for the sample heated at extreme conditions. $\mathrm{TiO}_{2}$ XANES spectra showed that the material is crystallized with rutile structure and is also thermally stable. SiC thin films were widely affected, showing an oxidation process as the time interval and intensity of the current increased. In addition, once the films were deposited over the $\mathrm{Cr}$ filament, their XANES spectra are quite different from the standard sample (deposited over $\mathrm{Si}$ ), even for the non-polarized microlamp, indicating a $\mathrm{Cr}$ contamination on the SiC structure.

\section{Introduction}

Microlamps as light sources in optical devices have been studied recently in several technical applications, such as wave-guides, IR micro spectroscopy, calibration of sensors and localized thermal treatment. They consist of a resistive filament heated by Joule effect when an electrical current flows throughout the material. The heated filament emits light with a wide range spectrum of radiation [1-3]. Most of the researches concerning the investigation of structural properties of the materials used in electronic microdevices deals with the study of their thin films alone or the interface between two of them. The investigation made in this work intents to study the top thin film (protective layer) already deposited on the microlamps, using $X$ ray Absorption Spectroscopy with a microfocus source of radiation available at LUCIA beam line of the synchrotron facility SOLEIL. The dimension of the spot $(3 \mu \mathrm{m} \times 3 \mu \mathrm{m})$ allows studying how the films properties are modified during the microlamp operation, exactly on the heat affected zone. It is reasonable to consider that the micro scale 18th Brazilian Workshop on Semiconductor Physics (BWSP 2017) dimensions and the substrate presence could affect the results when compared to the usual techniques.

\section{Methods and Results}

The microlamp produced in this work is shown schematically by figure 1 . It consists of a silicon nitride thin film deposited over silicon <100> wafer substrate where the chromium filament is deposited on. The filament is isolated from the environment by the last protective layer in order to avoid service break down if the filament oxidizes due to contact with air. Four different materials were used to make the protective layer: $\mathrm{SiC}, \mathrm{SiO}_{x} \mathrm{~N}_{\mathrm{y}}, \mathrm{AIN}$, and $\mathrm{TiO}_{2}$. The films were deposited by Plasma Enhanced Chemical Vapor deposition (PECVD) and sputtering, following previous studied conditions [4-6]. Table 1 shows the deposition parameters and the film thicknesses. The microlamps were polarized with different current and time, in order to simulate distinct operational conditions and to induce a different heating flow from the filament throughout the protective layer. The legends on figures 2 to 4 indicate the sample tags and polarization conditions. 


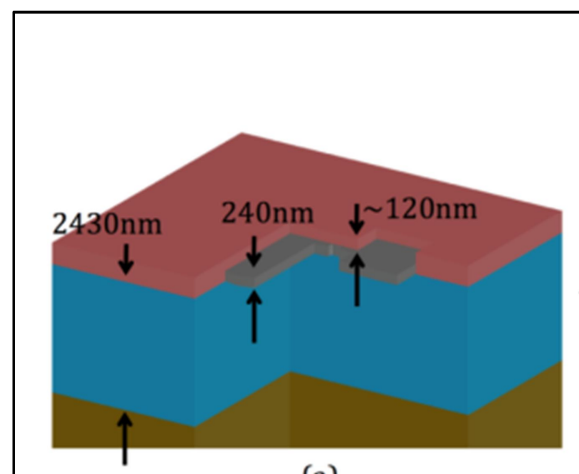

(a)

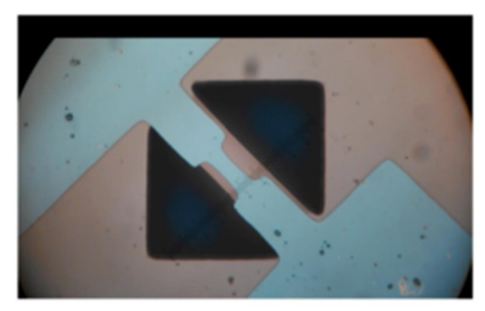

(c)

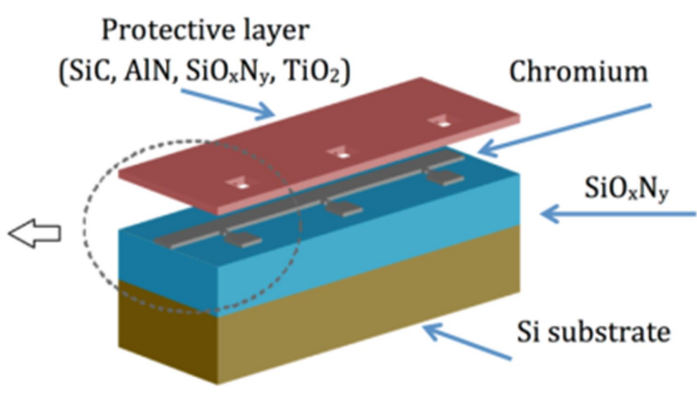

(b)

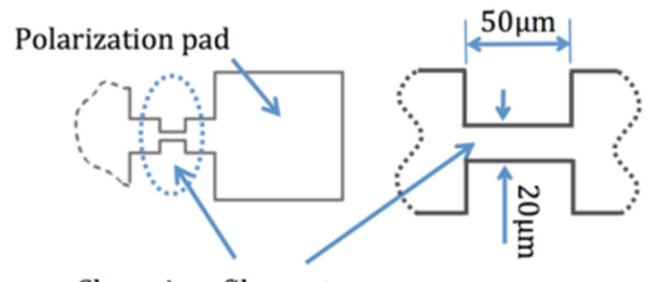

Chromium filament

(d)
Figure 1. Microlamp construction details. (a) and (b) The Cr filament is isolated from the environment by the top protective layer ( $\mathrm{SiC}, \mathrm{AIN}$, $\mathrm{SiO}_{x} \mathrm{~N}_{y}$ or $\mathrm{TiO}_{2}$ ) and the $\mathrm{SiO}_{x} \mathrm{~N}_{y}$ film. The device was constructed over $\mathrm{Si}$ substrate. (c) and (d) A microscope view of the filament and its main dimensions.
X-ray Absorption Near Edge Structure (XANES) measurements were carried out at synchrotron facility SOLEIL (LUCIA beam line) by Total Electron Yield using the own microlamp pads. The beam has a microfocus spot permitting to assess the protective layer just above the incandescent filament. Reference films were measured as well.

\section{Discussion}

Figures 2 to 4 show the XANES spectra obtained with the four distinct protective layers.

\section{- Silicon Carbide}

The Silicon Carbide XANES spectra are shown in figure 2. It is possible to visualize the changes produced by the heating as the device is submitted under increasing polarization conditions.

\begin{tabular}{|c|c|c|c|c|c|c|c|c|c|}
\hline \multirow[t]{2}{*}{ Film } & \multirow[t]{2}{*}{ Material } & \multirow{2}{*}{$\begin{array}{c}\text { Deposition } \\
\text { Process }\end{array}$} & \multicolumn{3}{|c|}{ Flux (sccm) } & \multirow{2}{*}{$\begin{array}{c}\text { Deposition } \\
\text { Temperature }\end{array}$} & \multirow[t]{2}{*}{ r. f. Power } & \multirow[t]{2}{*}{ Deposition Time } & \multirow[t]{2}{*}{ Thickness } \\
\hline & & & & & & & & & \\
\hline Insulator film & SiOxNy & PECVD & $\mathrm{N}_{2} \mathrm{O}: 45$ & $\mathrm{~N}_{2}: 30$ & $\mathrm{SiH}_{4}: 30$ & $320^{\circ} \mathrm{C}$ & $200 \mathrm{~W}$ & $2 \mathrm{~h} 30 \mathrm{~min}$ & $2,43 \mu \mathrm{m}$ \\
\hline \multirow[t]{3}{*}{ Filament } & $\mathrm{Cr}$ & Sputtering & Air: 10 & & & & $70 \mathrm{~W}$ & $20 \mathrm{~min}$ & $240 \mathrm{~nm}$ \\
\hline & Sic & PECVD & $\mathrm{SiH}_{4}: 3,6$ & $\mathrm{CH}_{4}: 32,4$ & $\mathrm{H}_{2}: 200$ & $320^{\circ} \mathrm{C}$ & $100 \mathrm{~W}$ & $25 \mathrm{~min}$ & $125 \mathrm{~nm}$ \\
\hline & SiOxNy & PECVD & $\mathrm{N}_{2} \mathrm{O}: 45$ & $\mathrm{~N}_{2}: 30$ & $\mathrm{SiH}_{4}: 30$ & $320^{\circ} \mathrm{C}$ & $200 \mathrm{~W}$ & $8 \mathrm{~min}$ & $114 \mathrm{~nm}$ \\
\hline \multicolumn{10}{|l|}{ Protective } \\
\hline \multirow[t]{2}{*}{ layer } & AIN & Sputtering & Air: 70 & $\mathrm{~N}_{2}: 30$ & & & $100 \mathrm{~W}$ & $30 \mathrm{~min}$ & $115 \mathrm{~nm}$ \\
\hline & $\mathrm{TiO} 2$ & Sputtering & Air: 60 & $\mathrm{O}_{2}: 40$ & & & $150 \mathrm{~W}$ & $83 \mathrm{~min}$ & $136 \mathrm{~nm}$ \\
\hline
\end{tabular}

18th Brazilian Workshop on Semiconductor Physics (BWSP 2017)
Comparing the samples curves with the references ( $\mathrm{SiC}$ and $\mathrm{SiO}_{2}$ ), the oxidation process is certainly observed by the increasing height of the peak at $\sim 1847 \mathrm{eV}$. Another interesting feature is the fact that the non-polarized microlamp (ML49-SiC) has a different spectrum compared to the bulk a-SiC standard sample. The figure 2 (inset) shows a displacement of the edge to lower energies and a broadening of the peak in $\sim 1843 \mathrm{eV}$, what indicates that the fabrication process results in modifications of the structure, possibly because of the presence of the chromium substrate.

\section{- Aluminum Nitride}

Figure 3 reveals that just minor changes are brought in the aluminum nitride XANES spectra by the heating process. The burned out sample (ML37-AIN) shows additional peaks indicating the crystallization of the film. A carefully comparison among ML53, 59, 
62 and 37-AIN (figure 3 inset) suggests that the crystallization process starts after $45 \mathrm{~mA}$ polarization, when the peak at $\sim 1567 \mathrm{eV}$ decreases and the one at $\sim 1572 \mathrm{eV}$ rises.

\section{- $\quad$ Silicon Oxynitride}

The similarity of the curves in figure 4 shows that the silicon oxynitride deposited as protective layer is stable under severe thermal conditions. The main peak in all samples $(\sim 1847 \mathrm{eV})$, when compared to

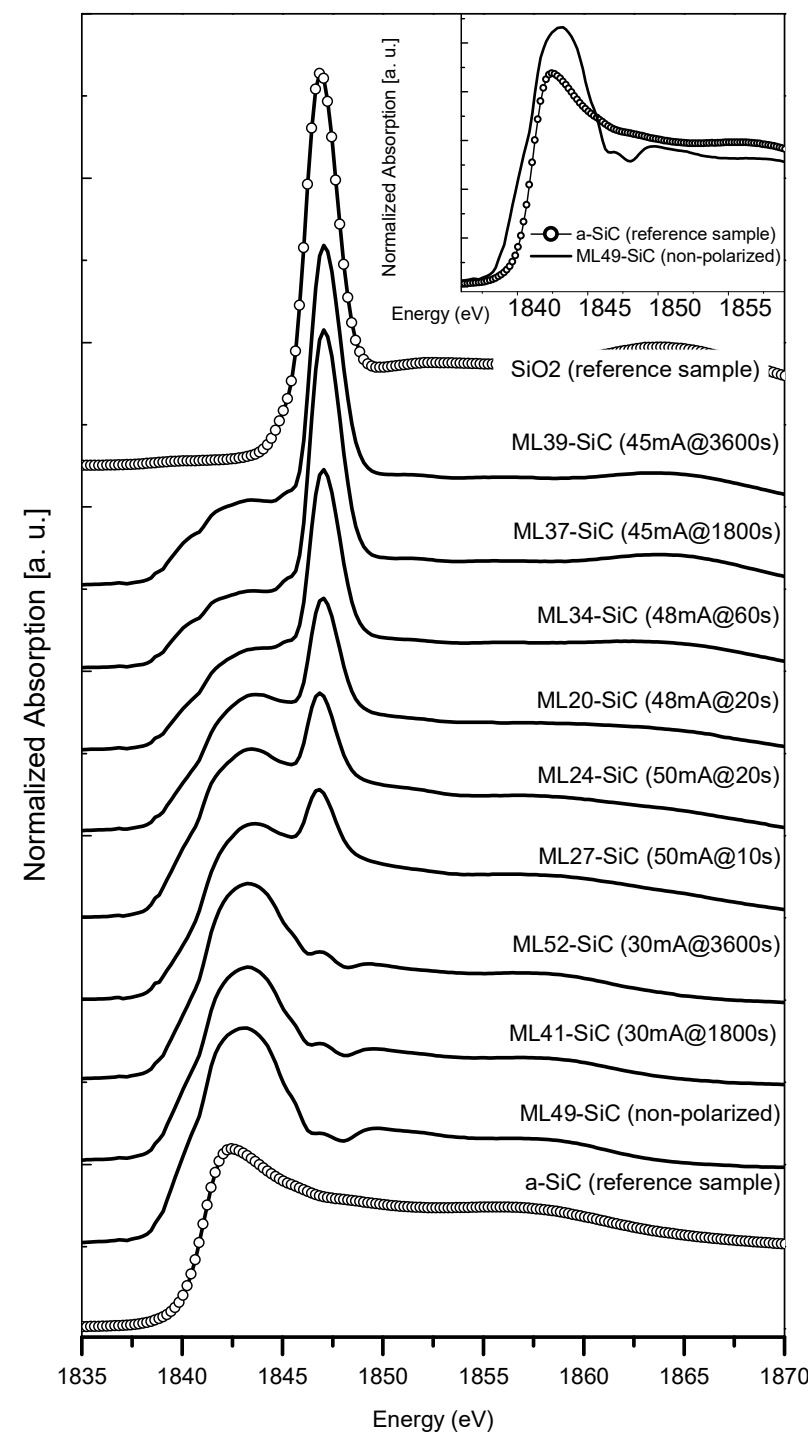

Figure 2. Si-K edge XANES spectra of the microlamps with SiC protective layer and some reference samples. The polarization conditions (electrical current and time) are indicated by the legends (the curves are stacked for better visualization). The inset figure shows non-stacked curves of the reference a-SiC and the non-polarized microlamp (ML-49) in order to facilitate the comparison.

18th Brazilian Workshop on Semiconductor Physics (BWSP 2017) standard $\mathrm{SiO}_{2}$, shows that the material is predominantly silicon dioxide.

\section{- Titanium Dioxide}

The XANES spectra obtained with the titanium dioxide samples indicates that the material is thermally stable as well. Comparing the standard sample with the microlamp spectra, it is possible to conclude that the structure is rutile crystalline.

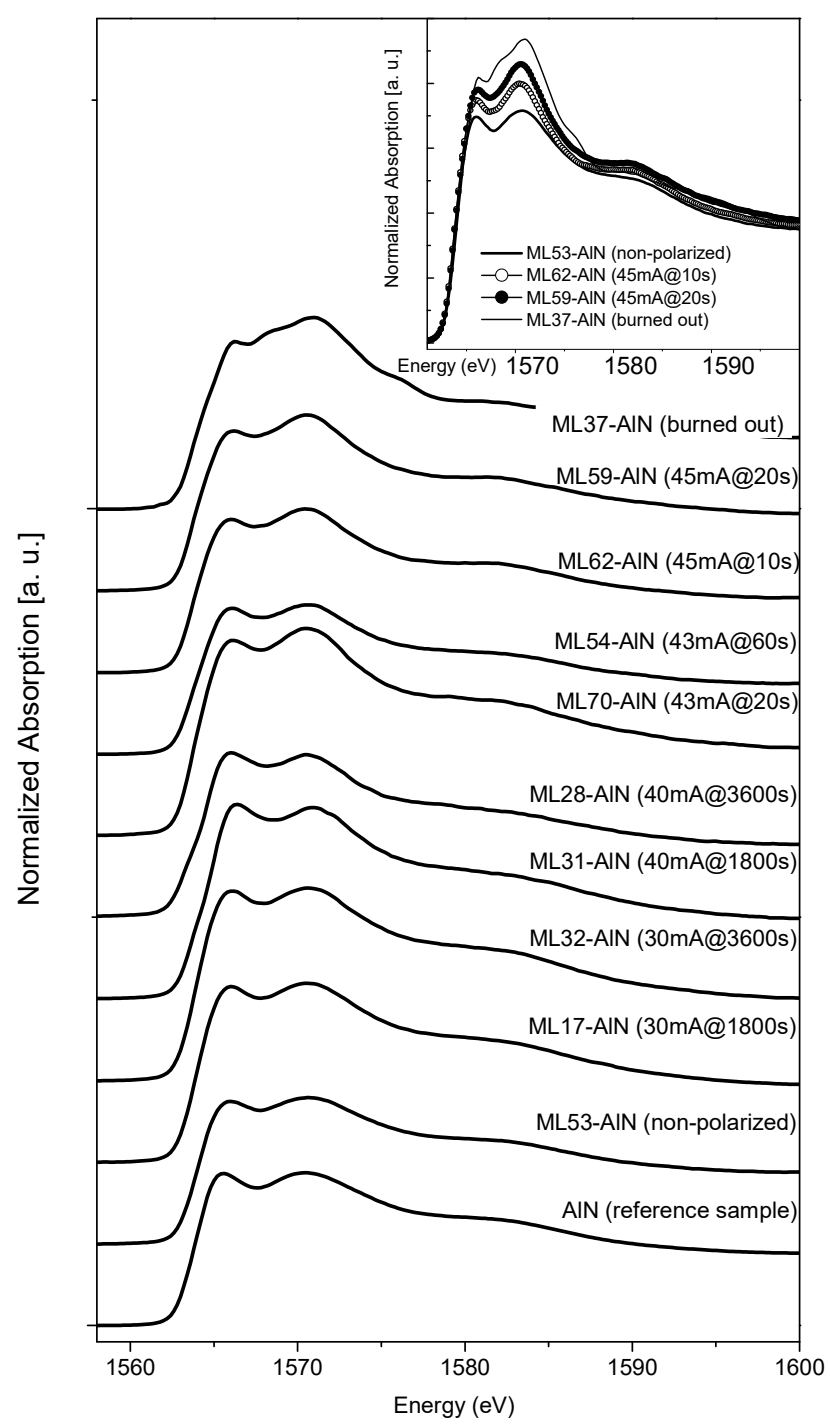

Figure 3. Al-K edge XANES spectra of the microlamps with the AIN protective layer and AIN reference sample. The curves are stacked for better visualization. The inset figure shows non-stacked curves of selected microlamps revealing the crystallization process. The polarization conditions (electrical current and time) are indicated by the legends 


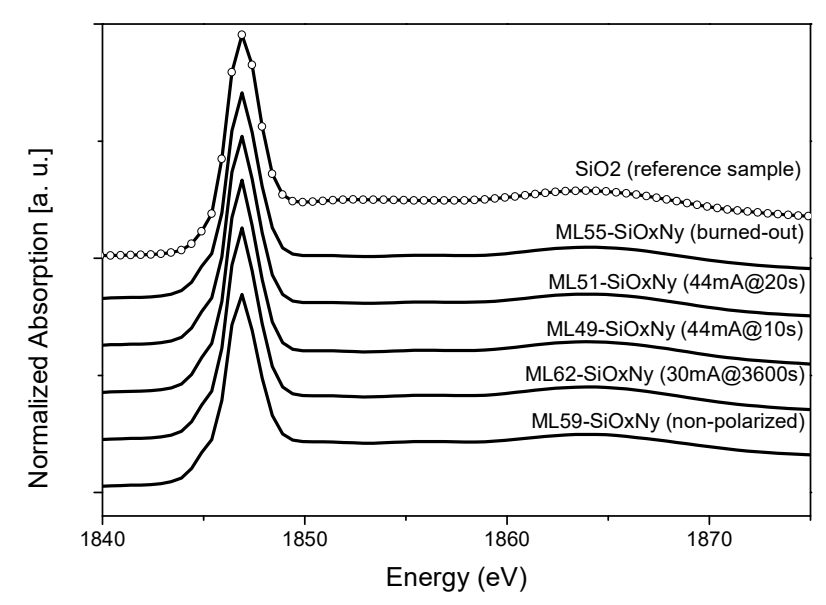

Figure 4. Si-K edge XANES spectra of the microlamps with $\mathrm{SiO}_{x} \mathrm{~N}_{y}$ protective layer and the $\mathrm{SiO}_{2}$ reference sample. The polarization conditions (electrical current and time) are indicated by the legends (the curves are stacked for better visualization).

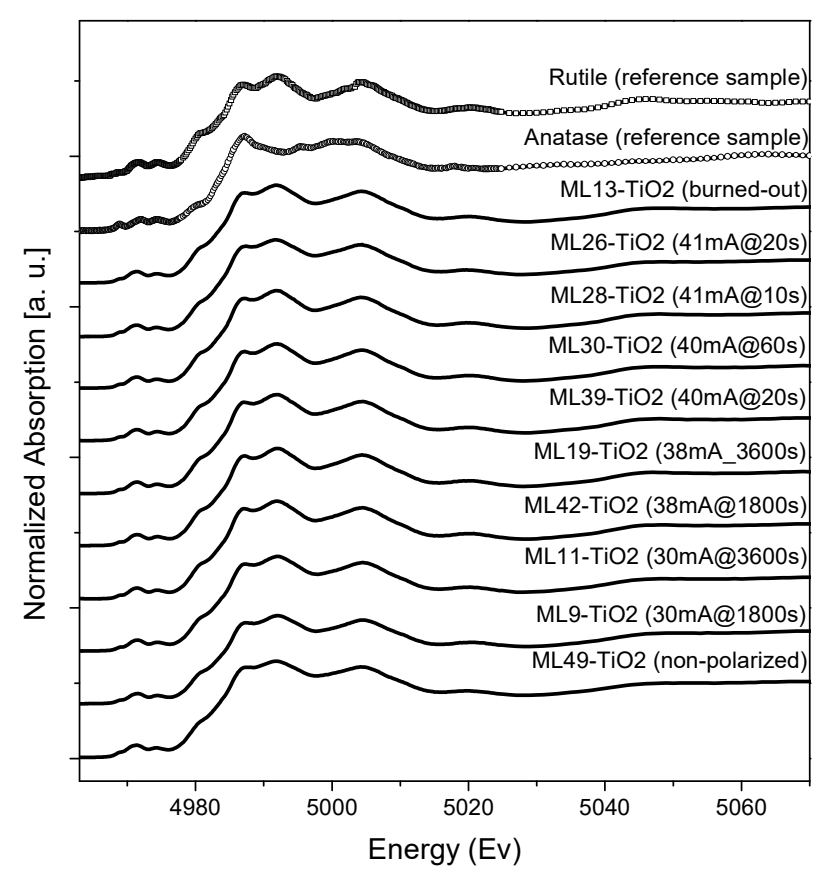

Figure 5. Ti-K edge XANES spectra of the microlamps with $\mathrm{TiO}_{2}$ protective layer and the rutile reference sample. The polarization conditions (electrical current and time) are indicated by the legends (the curves are stacked for better visualization).

\section{Conclusions}

The SiC XANES spectrum of the non-polarized microlamp is quite different than the a-SiC standard sample. This fact indicates that the chromium 18th Brazilian Workshop on Semiconductor Physics (BWSP 2017) substrate provides structural changes on SiC protective layer deposited over it. The edge displacement for lower energy values suggests that Si-Si or Si-Cr are present on the sample. After polarization the oxygen presence in the film is evident by the increasing peak at $1847 \mathrm{eV}$.

For the technological purposes the $\mathrm{SiO}_{x} \mathrm{~N}_{y}$ and the $\mathrm{TiO}_{2}$ protective layers are more suitable, considering their thermal stability properties, allowing microlamp long-term operation.

\section{Acknowledgments}

Thanks are due to CNPq and FAPESP for the financial support and SOLEIL Synchrotron Radiation Facility. I. Pereyra, M. C. A. Fantini, M. N. P. Carreño, M. I. Alayo and R. M. Cunha Junior are CNPq fellows and acknowledge its support.

\section{References}

1. D. O. Carvalho, M. N. P. Carreño, G. P. Rehder, M. I. Alayo, Integrated incandescent microlamp coupled to SiOxNy waveguide. Proc. SPIE 7208, MOEMS and Miniaturized Systems VIII, 72080 U

2. M. Ribeiro, I. Pereyra, M.I. Alayo, Silicon rich silicon oxynitride films for photoluminescence applications, Thin Solid Films 426 (2003) 200-204

3. M. I. Alayo, G. Rehder and, M. N. P. Carreño, MEMS-based incandescent microlamps for integrated optics applications, J. Opt. A: Pure Appl. Opt. 10 (2008) 104022

4. R. J. Prado, M. C. A. Fantini, M. H. Tabacniks, C. A. Villacorta Cardoso, I. Pereyra, A. M. Flank, Improvements on the local order of amorphous hydrogenated silicon carbide films. Journal of NonCrystalline Solids 283 (2001) 1

5. D. Criado, M. I. Alayo, I. Pereyra, M. C. A. Fantini, Structural analysis of silicon oxynitride films deposited by PECVD, Materials Science and Engineering B 112 (2004) 123

6. D. Criado, M. I. Alayo, M. C. A. Fantini, I. Pereyra Study of the mechanical and structural properties of silicon oxynitride films for optical applications, Journal of Non-Crystalline Solids 352 (2006) 2319 